\title{
A Amazônia em Rio 2: Clichês culturais cinematográficos para a promoção turística
}

\author{
The Amazon in Rio 2: \\ the clichés of cinema to promote tourism
}

\author{
Wilson de Souza Nogueira (NOGUEIRA, W. de S.) ${ }^{*}$ \\ Rafael de Figueiredo Lopes (LOPES, R. de F.)
}

RESUMO - No artigo se busca refletir acerca de clichês associados ao imaginário sobre o Brasil, especialmente, ao Rio de Janeiro e à Amazônia, a partir de cenas do filme de animação Rio2. O objetivo é compreender, pela perspectiva dos Ecossistemas Comunicacionais, reelaborações de aspectos culturais, produzidas para atender demandas da indústria cinematográfica, bem como suas imbricações com estratégias de desenvolvimento do turismo. A metodologia é baseada em revisão bibliográfica aliada à visualização e análise do filme. Pelo estudo, percebeu-se que o filme reproduz estereótipos consolidados no processo histórico e suscita aspectos de promoção ao turismo e megaeventos.

Palavras-chave: Turismo; Ecossistemas Comunicacionais; Rio 2; Imaginário; Clichês.

ABSTRACT - This paper exposes Brazilian stereotypes, especially relating to Rio de Janeiro and Amazon, through the movie Rio2. The goal is to understand the perspective of Communicational Ecosystems, reconfigurations of cultural aspects, to meet demands of the film industry and its overlapping with tourism development strategies. The methodology was the filmic analysis and literature review, contemplating the dialogue between various authors. It appears that the film reproduces stereotypes constructed by the historical process and displays aspects of promoting tourism and events.

Key words: Tourism; Ecosystem Communicational; Rio 2; Imaginary; Cultural clichés.

\footnotetext{
* Formação: Bacharelado em Ciências Sociais, Mestrado e Doutorado em Sociedade e Cultura na Amazônia, ambos pela Universidade Federal do Amazonas (UFAM). Atividade profissional: Professor do Programa de Pós-Graduação em Ciências da Comunicação (UFAM), integrante do Grupo de Pesquisa Mediação: comunicação e semiótica (UFAM/CNPQ). Endereço físico para correspondência: Av. Rodrigo Octavio, 1200. Coroado. CEP: 69067-005 - Manaus - Amazonas/AM - Brasil. E-mail: wilsonsouzanogueira@gmail.com.

** Formação: Bacharelado em Comunicação Social pela Universidade Federal de Roraima (UFRR), Mestrado em Ciências da Comunicação (UFAM), doutorando em Sociedade e Cultura na Amazônia (UFAM), integrante do Grupo de Pesquisa Mediação: comunicação e semiótica (UFAM/CNPQ). Endereço físico para correspondência: Av. Rodrigo Octavio, 1200. Coroado. CEP: 69067-005 - Manaus Amazonas/AM - Brasil. E-mail: rafaflopes@bol.com.br
} 


\section{INTRODUÇÃO}

Este artigo é uma abordagem multifacetada que ganhou forma pelo entrelaçamento das experiências de quatro pesquisadores brasileiros. Partiu-se da ideia de representação da Amazônia no cinema, que é a temática investigada pelo mestrando Rafael de Figueiredo Lopes, sob a orientação da Profa. Dra. Ítala Clay de Oliveira Freitas, no Programa de Pós-Graduação em Ciências da Comunicação da Universidade Federal do Amazonas (PPGCCOM/UFAM), mas ganhou um enfoque transdisciplinar, aproximando-se do imaginário e do turismo, a partir de outras atividades acadêmicas realizadas no PPGCCOM. O texto foi desenvolvido na disciplina de Tecnologias do Imaginário e Representações Culturais, ministrada pelo Prof. Dr. Wilson de Souza Nogueira e conectou-se ao projeto de estímulo à escrita científica realizado pela Profa. Dra. Maria Luiza Cardinale Baptista e às atividades promovidas pelo Amorcomtur! Grupo de Estudos em Comunicação, Turismo, Amorosidade e Autopoiese (CNPq).

No artigo se propõe uma reflexão sobre o filme de animação Rio 2 (Carlos Saldanha, 2014), pela análise de cenas, buscando referências ao imaginário sobre a cultura brasileira, bem como suas imbricações com estratégias da indústria do entretenimento, para promover o turismo e megaeventos realizados no Brasil (como Réveillon, Copa FIFA e Olimpíadas). O objetivo é compreender, pela perspectiva dos Ecossistemas Comunicacionais, reelaborações de aspectos culturais, produzidas para atender demandas da indústria cinematográfica, bem como suas imbricações com estratégias de desenvolvimento do turismo. Parte-se da hipótese de que o filme (re)cria o Rio de Janeiro e a Amazônia, por meio da representação baseada em clichês culturais e estereótipos sociais.

A partir desta premissa, considerou-se pertinente analisar Rio 2, pelo viés dos Ecossistemas Comunicacionais, perspectiva a partir da qual Colferai (2014) propõe uma abordagem múltipla, procurando compreender os fenômenos comunicativos, sem separar o ser humano da natureza e das tecnologias da comunicação e da informação. Estabelece-se, desse modo, um ecossistema comunicacional, como uma metáfora à biologia, inter-relacionando os seres vivos, o ambiente e a cultura, em uma trama complexa. 
Portanto, a intenção não foi fazer uma análise clássica, decompondo a obra cinematográfica. A proposta é aberta, tecida como uma renda ou uma teia. Sem desconsiderar os métodos e técnicas tradicionais de análise fílmica, pretendeu-se destacar elementos, partindo de percepções e impressões pessoais, entrelaçando e relacionando-as, num diálogo-trama, com pensamentos e conceitos de autores como Paes Loureiro (2015) e Soranz (2012), que ajudam a compreender como o imaginário se consolidou no processo histórico e suas reverberações no cinema. A contribuição de Silva (2006) vem complementar a temática, considerando que uma das possibilidades de cristalização de conteúdos simbólicos se dá pelo que o autor define como tecnologias do imaginário, sendo o cinema um dos mais poderosos dispositivos de produção de mitos e visões de mundo.

Além dos autores citados, Arendt (1995) ajuda a refletir sobre a questão dos clichês; Luís Nogueira (2010) amplia conceitos sobre gêneros cinematográficos e as particularidades da animação; Baitello Júnior (2014) pensa na cultura atual da imagem ("pasteurizada e homogeneizada"); e Freitas (2011) e Lohmann (2010) orientam considerações sobre turismo e megaeventos.

\section{O FILME}

O filme de animação infanto-juvenil Rio 2 (Carlos Saldanha, 2014) ${ }^{1}$, sequência de Rio, é uma produção hollywoodiana, concebida e dirigida por um brasileiro. O enredo $^{2}$ gira em torno de uma família de araras-azuis: o casal Blu e Jade, e os filhotes Carla, Bia e Tiago. Pela ambientação o filme poderia se chamar Amazônia, já que o Rio de Janeiro é apenas o ponto de partida da história, lugar de onde os protagonistas deixam a vida domesticada na cidade e se aventuram numa jornada selvagem, a fim de resgatar as suas origens na região amazônica.

\footnotetext{
${ }^{1}$ O filme foi analisado por meio de visualização on-line. Portal Filmes Online Grátis (2014). RIO 2. Direção: Carlos Saldanha. Produção: Blue Sky Studios/Fox Films, 2014, EUA, son., color., (101min). Disponível em: <http://www.filmesonlinegratis.net/assistir-rio-2-dublado-online.html>. Acesso em: 20/11/2015.

${ }^{2}$ Além da visualização on-line, as informações sobre enredo, personagens, contexto do projeto, produção e outros conteúdos relativos às obras citadas foram consultadas no site oficial. Rio - o filme (2014). Disponível em: <http://www.rio-ofilme.com.br/>. Acesso em: 08/12/2015.
} 
Após chegar à floresta, Jade reencontra seu pai, Eduardo, um sujeito durão, mas justo, que é o chefe do bando das araras-azuis (configurando, implicitamente, o cacique/chefe indígena), e Roberto, seu namorado de infância, o mais belo e forte do bando (representando o guerreiro). Blu demonstra dificuldade para se adaptar ao novo ambiente, lidar com as cobranças do sogro, o ciúme de Roberto e as diferenças culturais.

Os filhotes também vivenciam mudanças, na ruptura com o mundo tecnológico ao qual estão acostumados, para experimentarem o ritmo da natureza, entretanto, eles se adaptam com mais facilidade, quando comparados ao pai. A felicidade da família e dos demais animais, no entanto, é ameaçada, quando descobrem que a floresta está prestes a ser derrubada para atender à máfia da indústria madeireira. Os heróis ainda enfrentam um antigo inimigo, a cacatua Nigel (resgatando o conflito do primeiro filme). Trata-se de um dos vilões da história, que ao reencontrar Blu e Jade, na Amazônia, passa a persegui-los, no intuito de se vingar de ocorrências do passado.

Paralelamente, sucede a história de Túlio e Linda, um casal de cientistas, que luta pela preservação de animais ameaçados de extinção. Eles são os protetores conservacionistas de Blu e Jade, e estão na Amazônia realizando pesquisas científicas. Todas as subtramas (pesquisadores, madeireiros e Nigel) convergem para a mesma ação dramatúrgica: a mobilização de Blu a fim de evitar a destruição da Amazônia.

Vale ressaltar que a proposta deste texto não é o detalhamento do enredo, mas, para a discussão que se segue, apresentou-se uma síntese para situar o leitor. Nesse sentido, é pertinente salientar que, enquanto Rio 2 prioriza o problema do desmatamento, o primeiro filme da franquia gira em torno da questão do tráfico de animais silvestres, embora ambos não se detenham em aprofundar ou contextualizar tais problemáticas. A moral da história é dirigida ao público infanto-juvenil, mas reforça que os adultos precisam dar exemplos às novas gerações, para que seja possível uma "sociedade ecologicamente correta".

$\mathrm{O}$ roteiro de Rio 2 segue a estrutura tradicional das tramas de ação e aventura que, para Luís Nogueira (2010), apresenta fatos no tempo cronológico, desenvolvimento do conflito, clímax e o desfecho, baseando-se na luta do bem contra o mal (maniqueísmo), com personagens planos (sem complexidade psicológica), em ritmo narrativo acelerado, privilegiando cenas de impacto e incorporando situações que 
oscilam entre os códigos do humor e do melodrama. Isso, possivelmente, porque a subversão do modelo canônico do gênero é arriscada para uma produção focada no público infanto-juvenil e de altíssimo investimento.

A equipe de arte fez um rigoroso trabalho de reconstituição de ambientes, percebido em minúcias, ao retratar, por exemplo, o Rio de Janeiro e paisagens amazônicas, com formas e cores, que ganham nuanças, texturas e camadas de profundidade impressionantes. Uma atmosfera sensorial elaborada para os efeitos óticos na exibição em 3D.

Outro elemento importante é a trilha sonora. De acordo com os créditos do filme foi produzida pelo maestro inglês John Powell em coautoria com os músicos brasileiros Sérgio Mendes e Carlinhos Brown. Outros brasileiros como o cantor Milton Nascimento e os grupos Barbatuques e Uakti, participaram de faixas com referências a ritmos brasileiros, como Samba, Bossa Nova, Carimbó, Toada e Ciranda.

As personagens são interpretadas (dubladas) por famosos astros do cinema de Hollywood. Só para citar os protagonistas, destaca-se Jesse Eisenberg (Blu), Anne Hathaway (Jade), Rodrigo Santoro (Túlio), Leslie Mann (Linda) e Andy Garcia (Eduardo). A estratégia de utilizar a voz de atores conhecidos tem sido recorrente nas grandes produções de animação. Apenas dois brasileiros fazem parte do elenco Rodrigo Santoro e a cantora Bebel Gilberto, que interpreta Eva, uma tucana inspirada em Carmem Miranda.

\section{UM PRODUTO MIDIÁTICO ENTRE O IMAGINÁRIO E OS CLICHÊS}

Segundo Luís Nogueira (2010) a animação se inclina espontaneamente ao maravilhoso, fascinante e extraordinário, tendo como base infinitas elaborações imaginativas em seu processo criativo, de pluralidade técnica e estética. Para o autor, esse gênero convive pacificamente com a irrealidade, pois está no campo do sonho, da fantasia, da fabulação e das abstrações. É diferente do cinema convencional que, geralmente, procura a impressão do realismo ou naturalismo. A animação pode, conforme Luís Nogueira (2010, p. 59), "suspender, manipular, subverter, ou desafiar as leis da física, as normas culturais e as premissas éticas, etc.". 
Ao logo da história do cinema, a animação passou por inúmeras fases, que acompanharam o desenvolvimento tecnológico. Rio 2 foi desenvolvido durante três anos, nos laboratórios da Blue $S k y^{3}$, com os mais modernos recursos da chamada CGI (Computer Generated Imagery), ou seja, imagens geradas por computador. Vale ressaltar, contudo, que a técnica é considerada apenas uma ferramenta para conduzir a história, o talento dos artistas (roteiristas, designers, engenheiros de software, animadores, músicos, atores etc.) é o que estabelece empatia, emoção e impacto audiovisual.

A abordagem estética e ideológica sobre o espaço, o homem e a cultura, na animação Rio 2, instigou a reflexão sobre a representação do Brasil no cinema. A Amazônia, por exemplo, costuma ser restringida à exuberância de sua paisagem, aos aspectos folclóricos e os sujeitos são inferiorizados ou quase não têm destaque. $\mathrm{O}$ maniqueísmo, representado no conflito civilizado $\mathrm{x}$ selvagem, quase sempre fica evidente nas produções estrangeiras (e também nacionais) sobre a região. Segundo Soranz (2012) esse tipo de cinema busca referências desde as narrativas dos colonizadores do século XVI, passando pela literatura, pintura e fotografia, para inspirar suas criações. Resultando, geralmente, em filmes marcados pelo exotismo e afirmadores da "superioridade" do estrangeiro sobre as populações locais.

Conforme Paes Loureiro (2015) o isolamento histórico da Amazônia alimentou a construção de um imaginário acentuadamente folclorizante, fundado na visão etnocêntrica europeia. Assim, segundo o autor, a região foi sendo caracterizada como um "pesadelo febril" e seus povos como "caçadores de cabeças", "ignorantes", "preguiçosos". Desse modo, a ideologia da colonização configurou estereótipos que se propagaram no processo histórico e se mantém ao longo do tempo.

Por esse fluxo de pensamento, Rio 2 reverbera o imaginário colonizado pela ótica dos viajantes, cronistas, pintores, fotógrafos e cineastas de outrora. Araújo (2010) explica que os clichês no cinema são como fórmulas aplicadas a rotinas, situações, expressões linguísticas, objetos, símbolos, entre outras possibilidades comunicativas, que produzem concepções e comportamentos estereotipados. Esses padrões também são

\footnotetext{
${ }^{3}$ Produtora de animação e efeitos visuais subsidiária da distribuidora 20th Century Fox e responsável por filmes como a série A Era do Gelo (Carlos Saldanha, 2002; 2006; 2009; 2012), Robôs (Chris Wedge, 2005) e Bunny (Chris Wedge, 1998) vencedor do Oscar de melhor animação (ESTÚDIOS BLUE SKY, 2015).
} 
refletidos por Arendt (1995, p. 6), ao considerar que os clichês resultam da superficialidade e da falta de reflexão, uma espécie de autodefesa, pois a "[...] adesão a códigos de expressão e conduta convencionais e padronizados têm função socialmente reconhecida de nos proteger da realidade, ou seja, da exigência do pensamento feita por todos os fatos e acontecimentos em virtude de sua mera existência". Essa reflexão indica que a manutenção de ideias, símbolos e paradigmas está associada à comodidade de uma suposta segurança, contrapondo-se ao risco dos imprevisíveis efeitos da originalidade e da ousadia.

Quando ressaltados pela indústria do entretenimento, especialmente nos filmes, clichês e estereótipos tornam-se signos de fácil assimilação popular promovendo a espetacularização cultural. Essa configuração se alinha a ponderações feitas por Debord (1997) ressaltando a ideia de que a sociedade se contaminou pelas imagens disseminadas pelos meios de comunicação a ponto de transformar a cultura e as relações entre as pessoas em mercadoria.

O cinema, como uma indústria lucrativa, adota estratégias de marketing que dependendo dos desdobramentos determinam a valoração estética e econômica dos filmes, no intuito de compensar seus investimentos. Rio 2 além de lançar jogos, bonecos, revistas, roupas e outros atrativos que compõem seu catálogo mercadológico, possivelmente, faz um merchandising da Copa do Mundo de Futebol (Copa FIFA 2014), realizada três meses após o lançamento do filme. Basta ater-se à sequência da viagem das aves, do Rio de Janeiro para a Amazônia, na qual as personagens passam por cidades-sede do evento da FIFA, numa rota que não é a convencional entre o Rio e Manaus.

No roteiro, a justificativa se dá por uma falha no GPS utilizado para guiar o bando. Na metade do filme, no entanto, o destaque é para uma partida de futebol entre as araras-azuis e as araras-vermelhas. Para os produtores, tais estratégias foram utilizadas apenas para reforçar a diversidade da paisagem brasileira e ressaltar o futebol como a "paixão nacional". Além disso, obviamente, há uma analogia ao Festival Folclórico de Parintins, realizado na Amazônia, com a disputa entre o Boi Caprichoso (azul) e o Boi Garantido (vermelho), num cenário que lembra o Bumbódromo (local do festival) e com as araras torcedoras (galeras) ao redor. 


\section{DISCURSOS DO PRECONCEITO, NA SEDUÇÃO DOS CANIBALISMOS SIMBÓLICOS}

Na abertura do filme a tradicional vinheta da 20th Century Fox é apresentada em ritmo de samba. Logo surge a praia de Copacabana, adornada por gigantescos transatlânticos, prédios iluminados e milhares de pessoas confraternizando o Ano Novo. A primeira sequência, um "musical prólogo", com breves diálogos, numa visão romantizada do Brasil, apresenta bichos dançando, rodas de capoeira, rituais de candomblé e favelas com pessoas animadas. A sequência chega ao ápice, com uma explosão de fogos de artifícios iluminando a estátua do Cristo Redentor e a Baia de Guanabara, quando entra o letreiro: "RIO 2".

Corta para: AMAZÔNIA/EXTERNA/DIA. Imagens aéreas da Floresta Amazônica com rios sinuosos. Em seguida, a câmera adentra à selva e os sons da natureza se intensificam. Vê-se um casal de cientistas, Túlio e Linda, remando em uma canoa. Túlio liga um gravador e diz: "Estamos a 3.200 quilômetros do Rio de Janeiro, cercados por animais que lutam pela sobrevivência", no momento em que despencam numa cachoeira. A sequência traz a ideia dos pesquisadores do "mundo civilizado" que investigam o "imprevisível mundo selvagem”.

Fusão para: RIO/EXTERNA/INTERNA. Cenas ensolaradas do Rio de Janeiro com uma movimentação vibrante em suas praias, mostradas entre o recorte de enseadas de mar azul e montanhas. Numa reserva de Mata Atlântica se vê a casa de Blu e Jade (e de Túlio e Linda, que estão viajando). A família de aves, mantém hábitos urbanos (o que inclui comer panquecas com creme no café da manhã, usar escova de dente elétrica, computador, celular, iPod) e ao assistir uma reportagem na TV (com Túlio e Linda divulgando os avanços das pesquisas e a possibilidade de existir um santuário de ararasazuis), também resolve viajar para a Amazônia. Jade diz: "Não somos gente, somos pássaros, temos que ir à selva, ser pássaros, conhecer nossas raízes e ajudar Túlio e Linda".

Corta para: DIA/INTERNA/ESCRITÓRIO. A mesma reportagem é vista por um grande empresário do setor madeireiro que tem negócios na Amazônia. Ele se refere aos cientistas como "ecochatos" e demonstra preocupação quando a reportagem sinaliza que a Amazônia é um ecossistema fragilizado, devido ao desmatamento e ao avanço da 
agropecuária. Vê seus negócios ameaçados e diz que vai: "Resolver o caso com as próprias mãos". Possivelmente, essa situação esteja relacionada à ideia de uma "terra sem lei”, violenta e marcada por ações criminosas. Parece levar em consideração a repercussão internacional alcançada por conflitos na região, conforme Coutinho (2005) a exemplo da morte do seringalista Chico Mendes, em 1988, do assassinato de dezenove agricultores no Massacre de Eldorado dos Carajás, em 1996, e o caso da religiosa Dorothy Stang, em 2005.

Quando Blu anuncia aos amigos sobre a viagem o grupo se surpreende: "Amazônia? Nossa, que selvagem! Muito selvagem!”, diz um deles. "Lá tem mosquito que chupa teu sangue de canudinho", comenta outro. "Cobras que te engolem inteiro, piranhas carnívoras", enfatiza o terceiro, deixando o protagonista assustado. Vendo que o clima ficou tenso, vem mais um amigo e fala: “Ah essas histórias são puro exagero!", e resolve acompanhá-lo.

O filhote mais novo, Tiago, comemora a viagem descendo de uma corda, como numa imitação ao Tarzan, num cipó. Bia, a filha do meio, ao ler uma enciclopédia sobre a Amazônia, observa os animais perigosos que poderão encontrar, e Carla, a mais velha, diz que prefere ficar em casa. Ela muda de ideia, no entanto, quando os amigos Nico e Pedro revelam que vão à floresta, para descobrirem artistas e trazerem novidades para o Carnaval do Rio. A jovem se anima com a possibilidade de tornar-se uma caçadora de talentos (aludindo aos artistas que são levados de Parintins para o carnaval carioca por descobridores de talentos).

Ao longo do filme são apresentadas várias sequências musicais que poetizam situações narrativas, revelam sentimentos secretos das personagens ou contagiam as cenas com alegria. Na sequência "somos da mesma família", quando as araras da cidade encontram as araras da floresta, percebem-se elementos rítmicos e coreográficos de danças brasileiras como Carimbó, Toada, Funk Carioca, Ciranda e Quadrilha Junina, remixados no estilo pop music.

$\mathrm{Na}$ cena final as personagens se reúnem numa grande festa e a canção reforça que a floresta "é um tesouro esmeralda, o tempo voa suave como a brisa, é só pôr a tanga se alguém te chamar pra dançar". Jade pergunta a Blu: "Será que você vai fazer da Amazônia a sua casa, com o calor e os insetos?", e o marido responde: “Eu sou o rei da selva, selvagem total!", mas se assusta com uma aranha gigante que lhe cai sobre os 
ombros. Jade propõe sorrindo: "Podemos passar os verões no Rio...”. Blu se aproxima. Vistos de perfil, eles formam um coração: "Pra mim só existe você, Jade!".

Corta para um plano que reúne os animais cantando e dançando. A coreografia caleidoscópica lembra os grandes musicais de Hollywood. A paisagem noturna da floresta é iluminada pela fluorescência cintilante de flores e plantas que remetem a um lugar mágico. A câmera vai se afastando, enquanto botos saltam, jacarés se sacodem, macacos batucam em tartarugas, uma sucuri digere o empresário madeireiro, araras e tucanos voam em círculos e garças sambam em cima de vitórias-régias. A fauna da floresta executa um balé espetacular. Sobe som: "Leva na batida, bate o tambor, leva na batida, dá o show!”, e o filme que começou num megaevento no Rio de Janeiro termina como um grande espetáculo na Amazônia.

Visualiza-se na exposição de alguns aspectos abordados no filme, implícita ou explicitamente, a reprodução de preconceitos, clichês culturais e estereótipos sociais comumente expostos na mídia e no senso comum, por meio de imagens, sons, mensagens e ideias. Para Baitello Júnior (2014), simultaneamente, as pessoas devoram essas informações e são devoradas por elas. É o que chama de canibalismos simbólicos da cultura. Segundo o autor, a sociedade contemporânea tornou-se refém de um cotidiano sem tempo para refletir sobre os conteúdos que recebe e repassa, devido à exacerbação de informações e da produção imagética.

Neste texto traz-se a ideia de canibalismo associado à força dos produtos audiovisuais, dialogando com a perspectiva de Baitello Júnior (2014) que tece um fio condutor reflexivo desde a antropofagia ritual, praticada por tribos indígenas, passando pela antropofagia criativa e crítica dos artistas modernistas brasileiros até uma cultura universal da imagem, pasteurizada e homogeneizada, a qual se refere como a "era da iconofagia".

\section{RELAÇÕES ENTRE CINEMA, MEGAEVENTOS E ESTRATÉgIAS TURÍSTICAS NO BRASIL}

Combinar turismo, eventos, esportes e shows, tornou-se uma tendência mundial no intuito de atrair público, mídia e investidores. Conforme Freitas (2011) os 
megaeventos contemporâneos remetem a festas e rituais coletivos que sempre estiveram presentes na história da humanidade em diferentes culturas, mas se modificaram com o avanço tecnológico, estratégias publicitárias e as transformações sociais. Antes a celebração coletiva visava fortalecer laços comunitários, agora o homem contemporâneo vive uma situação paradoxal, porque ainda necessita do contato direto e da experiência grupal, mas está focado na satisfação narcisista. Os espaços festivos se tornam propícios para a união sem vínculos profundos e que dura o tempo da festa. Uma celebração de espetáculos mercantilizados e efêmeros. (FREITAS, 2011).

O Brasil, no senso comum, muitas vezes é caracterizado como um país turístico, festivo, colorido, musical e sensual (um megaevento por natureza!). Na canção salgueirense ${ }^{4}$, é a "terra do samba, da mulata e futebol". Os meios de comunicação, especialmente o cinema, reforçam essa ideia provocando inúmeros questionamentos. $\mathrm{O}$ Rio de Janeiro, por exemplo, é a cidade brasileira que recebe o maior número de turistas estrangeiros que viaja a lazer para o Brasil (São Paulo lidera o ranking de turismo de negócios), $40 \%$ dos estrangeiros que visitam o país passam pelo Rio, que na temporada de verão registra mais de três milhões de turistas, de acordo com o Instituto Brasileiro do Turismo (Embratur) ${ }^{5}$. Além de encantar os visitantes, com suas belezas naturais e patrimônio histórico, a cidade realiza inúmeros eventos. Conforme dados divulgados pela ICCA (Internacional Congress and Convention Association) ${ }^{6}$, entidade responsável por controlar e classificar as cidades que mais recebem eventos internacionais no mundo, entre eles a Jornada Mundial da Juventude (2013), a Copa FIFA (2014) e os Jogos Olímpicos (2016). Há também as festas tradicionais como o Carnaval, que segundo o Guiness Book ${ }^{7}$ é o maior do mundo e o Réveillon de Copacabana atraindo cerca de dois milhões de pessoas.

\footnotetext{
${ }^{4}$ Trecho do samba-enredo "Peguei um Ita no norte", de Demá Chagas, que proporcionou à Escola de Samba Salgueiro o título de campeã do carnaval carioca, em 1993. Disponível em: <http://www.salgueiro.com.br/carnavais>. Acesso em: 28/12/2015.

${ }^{5}$ Embratur. Disponível em:

<http://www.embratur.gov.br/piembratur-new/opencms/buscas/buscaAvancada.html>. Acesso em: 03/01/2016.

${ }^{6}$ ICCA. Disponível em: <http://www.iccaworld.com/>. Acesso em: 03/01/2016.

${ }^{7}$ Guiness World Records (GWR). Disponível em:

<http://www.guinnessworldrecords.com/world-records/largest-carnival>. Acesso em: 03/01/2016.
} 
De acordo com Lohmann (2010) os megaeventos potencializam as estratégias para fortalecer o turismo, podendo proporcionar melhorias em infraestrutura, movimentação na rede hoteleira, restaurantes, incremento no setor de serviços, aumento de empregos, obras de mobilidade urbana e criação de áreas de lazer para a população. Por outro lado, a autora não descarta a possibilidade de consequências negativas, como a má gestão e desvio de recursos financeiros, interferência nas comunidades envolvidas com a perda de suas identidades culturais, fracasso de políticas públicas, favorecimento ilícito de grupos empresariais e políticos, danos ambientais e sociais.

Em Firkowski; Baliski; Ferreira (2014) aponta-se que a promoção de megaeventos, no contexto da globalização, apresenta um discurso construído na ideia de desenvolvimento. Setores públicos e privados usam essa estratégia para justificarem grandes empreendimentos em um curto espaço de tempo, entretanto, conforme os autores, não tem sido uma alternativa que venha contribuindo para o desenvolvimento regional nem solucionando problemas urbanos e sociais.

[...] ao contrário, o modelo de cidade e de urbanismo que emerge sob tal perspectiva, tem apresentado resultados marcadamente acentuadores das desigualdades, já que ao mesmo tempo em que parcelas dos espaços são renovados em ritmo intenso e a prazo fixo, as receitas públicas e as políticas sociais ficam diretamente comprometidas, estas últimas principalmente em razão da inversão de prioridades e da necessidade de responder às demandas impostas pelo megaevento, mais que as urgências da sociedade local (FIRKOWSKY; BALISKI; FERREIRA, 2014).

No filme Rio 2, a comemoração da passagem de ano, no início da história, apresenta as personagens principais em pleno Réveillon de Copacabana. É pertinente ressaltar que a Fox Films (produtora e distribuidora do filme) foi uma das empresas patrocinadoras do evento, em 2013/14 ${ }^{8}$, período de pré-lançamento da animação. Já o primeiro filme da série deu mais ênfase ao Carnaval, inclusive, com sequências no sambódromo (local onde é realizado o desfile das escolas de samba). O clima carnavalesco, em Rio 2, também aparece em cenas na Amazônia, principalmente nas sequências musicais, com a exacerbação da fauna e da flora, retratando o Festival Folclórico de Parintins.

\footnotetext{
${ }^{8}$ Reportagem do site UOL sobre a festa de Réveillon temática, inspirada no filme Rio 2. UOL Brasil. Disponível em: <http://entretenimento.uol.com.br/noticias/redacao/2013/12/13/reveillon-de-copacabanatera-como-tema-a-animacao-rio-2.htm>. Acesso em 08/12/2015.
} 
Nessa perspectiva, percebe-se que o desenvolvimento do turismo pode ser acionado pelo cinema, atividade que Silva (2006) classifica como um exemplo de "tecnologia do imaginário", ou seja, um sistema capaz de cristalizar representações culturais ou apresentar modelos de "vida ideal" à sociedade. Rio 2, voltado ao público infanto-juvenil, também desperta afetividades nos espectadores adultos, contribuindo para imprimir uma imagem positiva do Brasil, podendo influenciar na escolha de destinos de viagem, tendo em vista que o filme mostra aspectos negativos sobre o país (como o tráfico de animais e a devastação da floresta), mas o clima festivo sobrepõe-se aos problemas, criando uma sensação de credibilidade e felicidade.

A relação do Brasil com o cinema internacional não é novidade. No caso do Rio de Janeiro, o período clássico de Hollywood, principalmente entre as décadas de 1930 e 1950, fixou no imaginário estrangeiro uma imagem de cidade exuberante, cosmopolita, charmosa e com gente acolhedora que celebra a vida com alegria. Já a partir dos anos de 1980 a imagem da "cidade maravilhosa" começou a ser associada a questões de violência, criminalidade e refúgio de bandidos, de certa maneira abalando a imagem charmosa do Rio (LABAKI, 1998). As representações estereotipadas ou violentas, entretanto, não foram exaltadas apenas por Hollywood, mas em filmes nacionais, de grande repercussão, como Cidade de Deus (Meirelles, 2002) e Tropa de Elite (Padilha, 2007).

A Amazônia, por outro lado, sempre foi mais associada à natureza selvagem, ao isolamento e ao caráter mítico. Conforme Soranz (2012) uma das tendências reforça questões sobre o ambiente inóspito e aberrações, como animais perigosos ou préhistóricos convivendo com grupos humanos, lendas, mistérios e a busca por tesouros, como Eldorado (a cidade de ouro). Outra abordagem comum é representar as etnias indígenas como seres incultos e atrasados intelectualmente, sem a preocupação de caracterizar e contextualizar a diversidade humana que há na região. Contemporaneamente, a Amazônia costuma ser mais retratada como símbolo da ecologia e da sustentabilidade ou um território marcado por conflitos étnicos, devastação da natureza e disputa por terras.

Portanto, o filme Rio 2 conecta o Rio de Janeiro à Amazônia, por meio de clichês e estereótipos, para facilitar a relação de identidade com o público, apelando a emoções ou referências prévias, conforme a ideia de clichês no cinema, compreendida 
por Araújo (2010). Desse modo, descarta a multiplicidade e particularidades da região onde é ambientado, diante da dificuldade de abordar as temáticas do enredo com mais contundência, já que a Amazônia é uma área com cerca de 7 milhões de $\mathrm{km}^{2}$, que se estende por nove países da América do Sul (Brasil, Bolívia, Peru, Equador, Colômbia, Venezuela, Guiana, Guiana Francesa e Suriname); a região tem a maior bacia hidrográfica e um dos biomas mais ricos do planeta, além de grande diversidade étnica, cultural e econômica (BECKER, 2006).

Amazônia brasileira, chamada de Amazônia Legal, ocupa $61 \%$ do território nacional (compreendendo os estados do Acre, Amapá, Amazonas, Pará e Tocantins, Mato Grosso, e parte do Maranhão), uma área sete vezes maior que a França, no entanto, comparada a outras regiões do país ainda é carente em infraestrutura e serviços, mas o maior desafio é criar estratégias para fomentar o desenvolvimento sustentável, minimizando impactos negativos à biodiversidade, com a participação das comunidades e não apenas beneficiando grupos empresariais ou políticos (BECKER, 2006).

No Estado do Amazonas, o maior do Brasil, dados de uma pesquisa da Amazonastur $^{9}$ (Empresa Estadual de Turismo), sobre a movimentação turística no período da Copa de 2014, apontaram a visita de 260 mil turistas, o que representou um crescimento de $45 \%$ no fluxo de pessoas, comparado ao mesmo período do ano anterior. O mesmo estudo indicou que a comercialização de cerveja aumentou em 30\%, houve queda de $3 \%$ no índice de criminalidade e a taxa de satisfação dos turistas foi de $80 \%$. Ainda de acordo com a pesquisa, muitos estrangeiros relataram que se surpreenderam com a hospitalidade e cultura local, pois, conforme informaram na pesquisa, tabloides europeus alertaram sobre a violência, o calor e a presença de animais selvagens nas ruas.

A questão do exótico e dos clichês culturais é complexa, já que a "autoexotização" também é um recurso para promover o turismo regional, como é possível perceber no site do Amazonastur (2016), por meio de uma linguagem que alimenta extravagâncias. O slogan "Amazonas: destino verde do Brasil", ilustrado com imagens da floresta e da fauna sugere um paraíso ecológico, apresentando informações úteis para turistas, reportagens, estatísticas, dicas e opções de roteiros. O reforço dos clichês, para atrair o interesse turístico, é notado tanto pelo discurso textual quanto pelas

\footnotetext{
9 Amazonastur. Disponível em: <http://www.visitamazonas.am.gov.br/site/amazonastur>. Acesso em: 07/01/2016
} 
imagens de divulgação dos passeios, entre eles o "Encontro das Águas: um dos mais belos mistérios da natureza, onde os rios Negro e Solimões formam o Amazonas". Também são oferecidos roteiros temáticos, que aliam conforto natural de hotéis flutuantes, com pescarias de piranhas e focagem noturna de jacarés, esclarecendo que "os guias os capturam com as mãos, realizam explicações, fotografias e os retornam ao habitat natural". Nas visitas à comunidades ribeirinhas, o turista pode assistir a encenação de "rituais indígenas e comprar peças do artesanato local". Em Novo Airão, os visitantes desvendam o Refúgio Arambóia "onde são criadas jiboias de diversas espécimes", e podem "conhecer bem de perto os botos cor-de-rosa, alimentá-los e nadar com estes interessantes mamíferos". Em Presidente Figueiredo, local conhecido como a "Terra das cachoeiras e das mais belas cascatas e cavernas do Amazonas", o cenário é ideal para aventura e esportes radicais (AMAZONASTUR, 2016).

\section{CONSIDERAÇÕES FINAIS}

O cinema é uma arte que produz sentidos, por meio de imagens e sons, em dimensões objetivas e subjetivas, mas também é uma indústria com metas estabelecidas e focadas em ações para gerar lucro. As abordagens podem seduzir de diferentes maneiras, inclusive, disfarçadas no discurso de um mundo mais sustentável ou oferecendo uma viagem paradisíaca e repleta de aventuras. Se a ficção, enquanto gênero se exime do compromisso com a realidade, na animação vai além, podendo subverter quaisquer convenções. O que torna até mesmo um desenho animado infantil, como Rio 2, num produto ideológico e estratégico do ponto de vista capitalista. Podendo ser um instrumento de promoção turística em função de sua mensagem implícita na representação dos lugares ambientados no filme. Já no que diz à proposta de desenvolvimento socioeconômica dos megaeventos, percebe-se que a ideia raramente consolida-se na dimensão pragmática, pois geralmente atendem aos interesses das elites econômicas.

Em Rio 2, a força criativa (enquanto obra audiovisual), reconfigurada pelo imaginário social, que há séculos vem sendo construído, pode imprimir uma leitura superficial, limitando a compreensão do Brasil e reforçando preconceitos. Como um 
produto de entretenimento, diverte o público e proporciona o retorno financeiro aos produtores. Além disso, como se salientou, a inter-relação com a promoção do turismo e de megaeventos, demonstra o quão abrangente é o impacto do filme. Essa percepção, não pretende ser relativista, tomar qualquer partido ou juízo de valores, mas proporcionar uma visão dialógica, pela qual os conhecimentos e significados se constroem na interação e no debate, como propõe a perspectiva dos Ecossistemas Comunicacionais.

Ao tomar-se como exemplo o setor do turismo, pode-se supor que a atividade seria uma alternativa, em potencial, para o desenvolvimento econômico, especialmente, na Amazônia. Para tornar-se um segmento competitivo, contudo, atendendo às exigências do mercado, seria preciso investir em infraestrutura, superar desafios que passam pela inclusão social, capacitação de trabalhadores, preservação do meio ambiente e a valorização cultural. Mas, até que ponto isso é pertinente? O discurso de desenvolvimento sustentável é viável na prática? Um Brazil tipo exportação é útil para a sua população ou beneficia apenas aos interesses de pequenos grupos?

Tais reflexões estão longe de encontrar respostas definitivas, isso, aliás, é incabível quando se decidiu analisar uma trama complexa entre diferentes sistemas sociais. Mas, as pistas sobre o imaginário colonizado no processo histórico, o autoexotismo, as remixagens simbólicas dos canibalismos culturais, bem como os interesses comerciais derivados da indústria cinematográfica, transcendem o caso específico de um filme e ampliam as ponderações em relação à identidade brasileira e às possibilidades para o desenvolvimento regional. É preciso abrir o diálogo aos diversos pontos de vista, afinal, as contradições fazem parte da condição humana.

\section{REFERÊNCIAS}

AMAZONASTUR. Empresa Estadual de Turismo/AM. Disponível em: <http://www.visitamazonas.am.gov.br/site/amazonastur>. Acesso em: 07/01/2016.

ARENDT, H. A vida do espírito: o pensar, o querer, o julgar. Rio de Janeiro: Relume Dumará, 1995. 
ARAÚJO, V. L. Ser ou Não Ser Natural, Eis a Questão dos clichês de Emoção na Tradução Audiovisual. Tese de Doutorado. São Paulo: Universidade de São Paulo, 2010.

BAITELlO JUNIOR, N. A era da iconofagia: reflexões sobre a imagem, comunicação, mídia e cultura. São Paulo: Editora Paulus, 2014.

BECKER, B. Amazônia: geopolítica na virada do III milênio. 2. ed. Rio de Janeiro: Garamond, 2006.

COLFERAI, S. Um jeito amazônida de ser mundo - a Amazônia como metáfora do ecossistema comunicacional: uma leitura do conceito a partir da região. Tese de Doutorado. Manaus: Universidade Federal do Amazonas, 2014.

COUTINHO, L. A mártir da floresta. In: Revista Veja. Rio de Janeiro, p. 53-61, 23.fev.2005.

DEBORD, G. A sociedade do Espetáculo. Rio de Janeiro: Contraponto, 1997.

EMBRATUR. Disponível em: <http://www.embratur.gov.br/piembraturnew/opencms/buscas/buscaAvancada.html>. Acesso em: 03/01/2016.

ESTÚDIOS BLUE SKY. Disponível em: <http://blueskystudios.com/>. Acesso em: 20/11/2015.

FIRKOWSKI, O. L. C. de F.; BALISKI, P.; FERREIRA, A. G. Copa do Mundo no Brasil: entre expectativas elevadas e benefícios imprecisos. Turismo e Sociedade, [S.1.], v. 7, n. 1, jan. 2014. ISSN 1983-5442. Disponível em: <http://revistas.ufpr.br/turismo/article/view/37137/22887>. Acesso em: 15/04/2017.

FREITAS, R. F. Folia, mediações e megaeventos. Revista Rumores. São Paulo: Universidade de São Paulo/USP, edição 9, jan.-jun, 2011.

GRES ACADÊMICOS DO SALGUEIRO. Disponível em: $<$ http://www.salgueiro.com.br/carnavais>. Acesso em: 28/12/2015.

GUINESS WORLD RECORDS (GWR). Disponível em: <http://www.guinnessworldrecords.com/world-records/largest-carnival>. Acesso em: 03/01/2016.

ICCA. Internacional Congress and Convention Association. Disponível em: $<$ http://www.iccaworld.com/>. Acesso em: 03/01/2016.

LABAKI Amir (Org.) O cinema brasileiro. São Paulo: Publifolha, 1998.

LOHMANN, P. Megaeventos esportivos: impactos no turismo das cidades sedes. Dissertação de Mestrado. Gestão Empresarial. Rio de Janeiro: Fundação Getúlio Vargas, 2010. 
NOGUEIRA, L. Manuais de Cinema II - Gêneros cinematográficos. Covilhã: LabCom Books, 2010.

MEIRELLES, F. Cidade de Deus. Videofilmes/O2 Filmes. Cor, 130min. Brasil, 2002.

PAES LOUREIRO, J. Cultura amazônica - Uma poética do imaginário. Manaus: Editora Valer, 2015.

PADILHA, J. Tropa de Elite. Universal Pictures do Brasil. Cor, 118 min. Brasil, 2007.

PORTAL FILMES ONLINE GRÁTIS. Disponível em: <http://www.filmesonlinegratis.net>. Acesso em: 20/11/2015.

RIO - o filme. Disponível em: <http://www.rio-ofilme.com.br/>. Acesso em: 08/12/2015.

SALDANHA, C. Rio 2. Filme de animação produzido por Blue Sky Studios/Fox Films, 2014, EUA, son., cor., (101min). Disponível em: $<$ http://www.filmesonlinegratis.net/assistir-rio-2-dublado-online.html>. Acesso em: $20 / 11 / 2015$.

SILVA, J. M. As tecnologias do imaginário. Porto Alegre: Sulina, 2006.

SORANZ, G. Território imaginado: imagens da Amazônia no cinema. Manaus: Edições Muiraquitã, 2012.

UOL - Reveillon de Copacabana com temática do filme Rio2. Disponível em: $<$ http://entretenimento.uol.com.br/noticias/redacao/2013/12/13/reveillon-decopacabana-tera-como-tema-a-animacao-rio-2.htm>. Acesso em 08/12/2015.

Recebido em: 29-09-2016.

Aprovado em: 29-08-2016. 